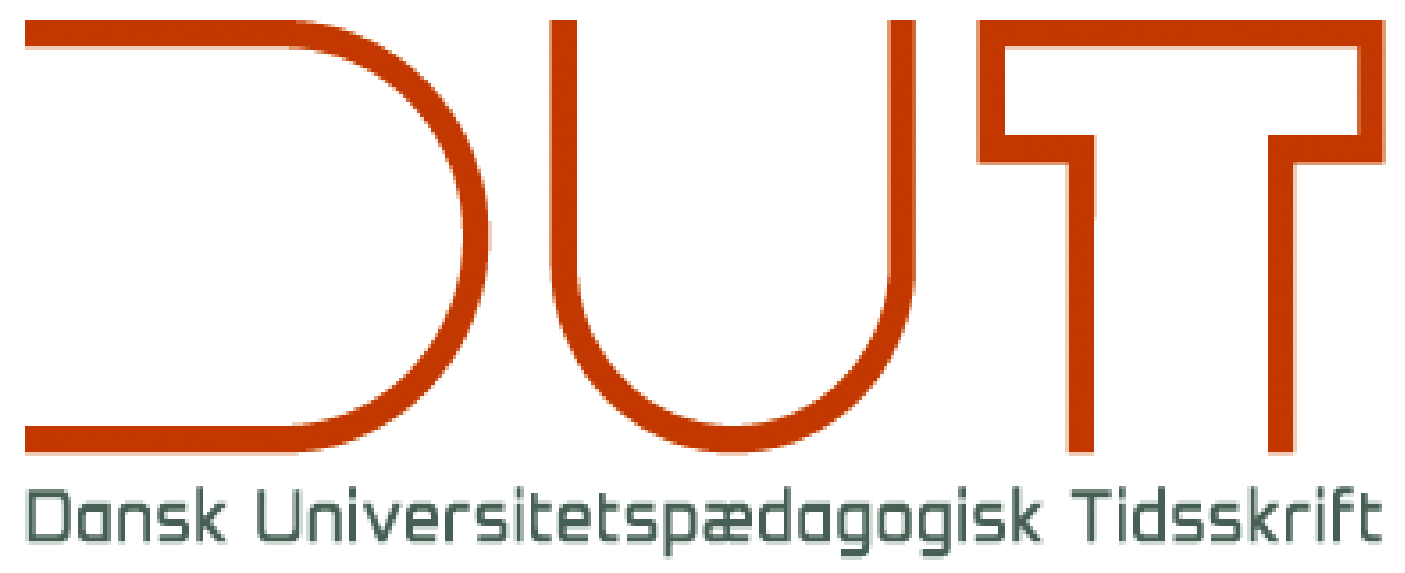

Universitetspædagogikum

Årgang 13 nr. 25 / 2018

Titel

Forfatter

Sidetal

Udgivet af

URL

Introducing complexity and uncertainty of environmental models in the education of future engineers

Luca Vezzaro

$194-210$

Dansk Universitetspædagogisk Netværk, DUN

> http://dun-net.dk/

Betingelser for brug af denne artikel

(c) Copyright
Denne artikel er omfattet af ophavsretsloven, og der må citeres fra den. Følgende betingelser skal dog være opfyldt:

- Citatet skal være i overensstemmelse med "god skik"

- Der må kun citeres „i det omfang, som betinges af formålet“

- Ophavsmanden til teksten skal krediteres, og kilden skal angives ift. ovenstående bibliografiske oplysninger.

DUT og artiklens forfatter 


\section{Introducing complexity and uncertainty of environmental models in the education of future engineers}

Luca Vezzaro, Associate Professor, Department of Environmental Engineering, DTU Environment

\section{Practice paper, peer-reviewed}

Environmental models are affected by significant sources of uncertainties compared to other engineering fields. However, traditional courses tend to provide a deterministic perspective, where the various sources of uncertainty (e.g. model structure, input data, implementation) are often neglected. This issue was highlighted during a university teachers' training programme, where the trainee proposed a solution that aimed to improve student understanding of uncertainty sources. The proposed solution was implemented in an existing MSc course (with 90 students). The course, originally based on problem-solving group work, was revised by introducing an assignment inspired by Problem-Based Learning, which can be used to introduce engineering students to complex issues. The new assignment introduced the students to new uncertainty sources (model structural and technical uncertainty) that are essential in the development and application of environmental models. The effects of the new approach on the students' learning were monitored by using course evaluation questionnaires and written feedback from the students. The open-ended assignment challenged the common habits of the students, highlighting the subjectivity in model applications and result interpretation. The students' response was mixed, with major concerns linked to the high workload, which limited the time for deep reflection. Nevertheless, the learning objectives were successfully achieved, providing future environmental engineers with better understanding of the complexity of environmental modelling.

\section{Introduction}

Mathematical models are essential tools that are used by environmental engineers to understand the behaviour of environmental systems and to predict the effect of possible strategies e.g. to assess pollution impacts, to predict the effect of different solutions on natural ecosystems and to design pollution control options. The complexity of environmental systems results in a great number of inherent sources of uncertainty, which therefore affect the outcomes of these engineering tools (Beven, 2009; Voinov and Shugart, 2013). Although sources of uncertainties in environmental modelling have thoroughly been investigated in the scientific literature (Warmink et al., 2010; Warmink et al., 2017; Matott et al., 2009; Refsgaard et al., 2007), the application of uncertainty analysis is still limited in practice (Beven, 2009). This issue is 
also reflected in teaching programmes, where students are often provided with a deterministic vision of the model building and application process. The model building procedure is often schematized in an iterative step process (e.g. Carstensen et al., 1997; Jakeman et al., 2006) ending in a single solution.

Existing engineering courses traditionally follow this step-wise structure, but limited time is allocated to result interpretation and uncertainty assessment. During a training programme for university teachers, the author identified this as an important issue in the education of future environmental engineers. Teachers' feedback from specialized courses (e.g. courses from the last year of MSc education) underlined the students' need for handling the various sources of uncertainty affecting their modelling results in a more proficient manner. The author thus proposed a modification of an existing MSc introductory course on environmental modelling, based on the following concepts:

- There are several modelling approaches that can be used to solve environmental problems (model structure uncertainty)

- Modelling results are affected by several sources of uncertainty, including subjective choices made by the modeller him/herself (model technical uncertainty).

Enabling students to face the complexity stemming from 'real world' situations is among one of the strengths of Problem-Based Learning (PBL) (Zhou, 2012). However, a 'pure' PBL approach could not be applied due to logistical issues (see also the discussion in Holgaard et al., 2017), and a modified PBL approach was adopted. The course modifications were discussed with fellow university teachers (following the same training programme) and teaching counsellors before implementation. This new course structure was only applied to the final course module, specifically dealing with uncertainty analysis.

This article aims at showing how understanding of different sources of uncertainty can be introduced within the structure of existing environmental modelling courses. Specifically, the new approach introduced the students to model structural uncertainty and model technical uncertainty. The current course is first introduced, followed by a description of the new assignment and all the evaluation tools that were utilized to monitor the implementation of the new module. Finally, there is an overview of the results from the first three cohorts who took the new course.

\section{Material and methods}

\section{Course description}

The course (hereafter defined as EnvMod) is a 10 ECTS compulsory course that is taught on the first semester of a MSc programme on Environmental Engineering. EnvMod aims at introducing the basic concepts of environmental modelling to the 
first-year MSc students and it represents one of the pillars of the entire MSc programme, since several other courses rely on the concepts introduced in the EnvMod.

EnvMod is organized around five modules, where students have to solve practical environmental problems and deliver a report for each module. Work is carried out by groups of four students, with a formative evaluation and a final oral exam focusing on the best reports of each group.

Auditorium-based teaching is reduced to short lectures (maximum 30-45 minutes twice per week), with most of the teaching activity taking place in the computer room, working on the five assignments. The topics of the assignments are directly linked to the research activities of teachers and teaching assistants: the assignments are therefore changed every 2-3 years in order to keep them updated with the changing teaching assistants and the latest developments in research.

The level and background of the EnvMod students is heterogeneous: $58 \%$ of the students (57 out of 98 students- data for 2015) have a BSc from other universities (both Danish and foreign). This variety results in a broad range of experiences: depending on country of origin and previous educations, students can either have a strong background in mathematical modelling or be completely unfamiliar with the core elements of the course.

The learning objectives of EnvMod cover all the medium-low levels of understanding in Bloom's (SOLO) taxonomy (Biggs and Tang, 2011). The engineering skills developed by the students in EnvMod include the ability to (a) use different models and software to solve a range of environmental problems, (b) interpret and present simulation results, (c) apply models and critically analyse their results with respect to measurements from natural systems.

The core elements of the course follow the classical structure for model development (Figure 1): (i) formulation of environmental problems, (ii) analysis of available data, (iii) definition of model structure, (iv) diagnostics of the model, (v) evaluation of model performance and (vi) model application. The development of the modules follows the model building framework, (e.g. Module 1 and 2 focus on points i-iii), with model application (point vi) common to all the modules. These core elements are general and they are useful in any environmental field, i.e. the students will use them irrespective of which study line he/she will choose and which field of environmental engineering he/she will work in after graduation. This is stressed by the fact that (as mentioned earlier), the actual content of the modules (e.g. which model is applied, which environmental problem is analysed) depends on the teachers and teaching assistant of the course, i.e. they change every 2-3 years. 

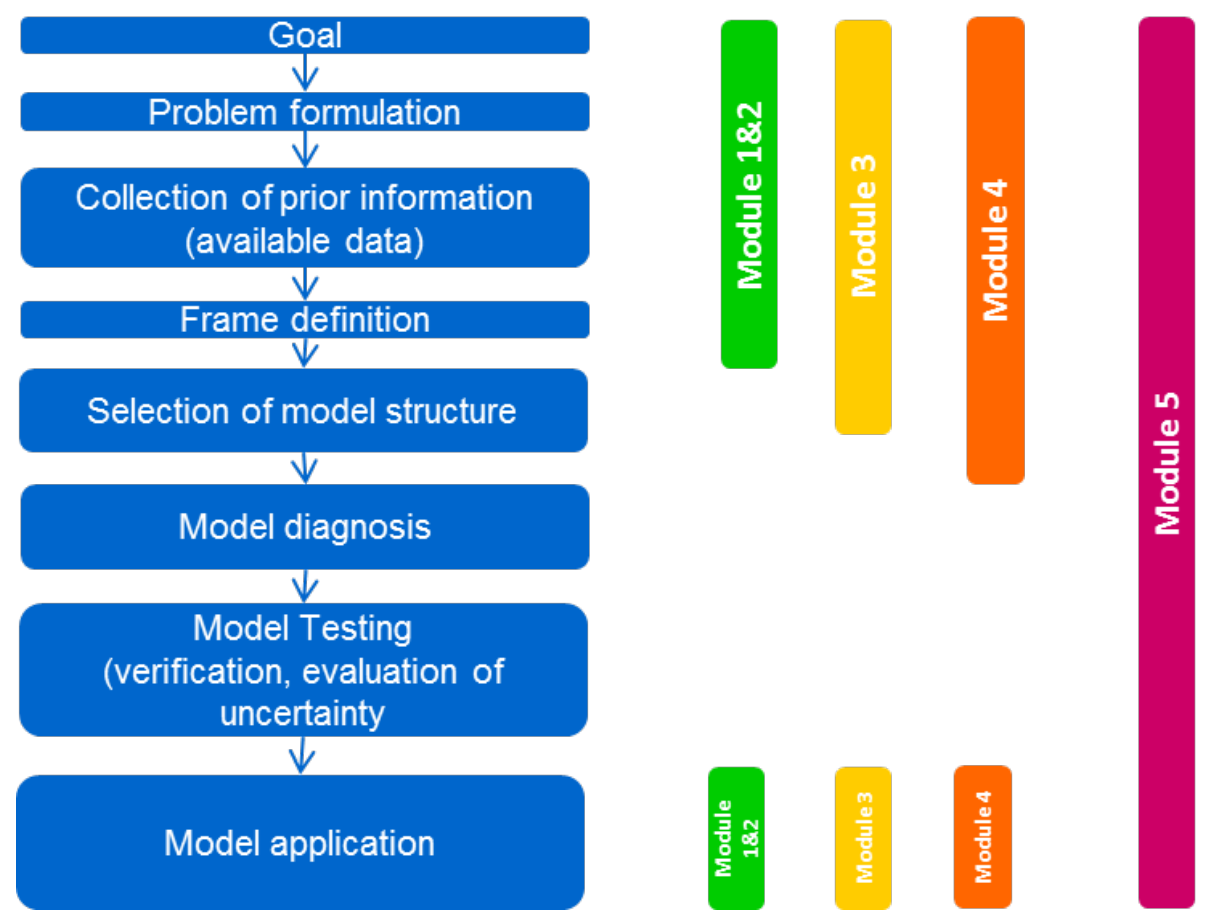

Figure 1: Schematic representation of model building exercise (adapted from Carstensen et al., 1996) and relation to the modules in the EnvMod course.

The core elements and the learning objectives develop in parallel, with the coreelements linked to the lower level of understanding dealt with in the first modules, while higher understanding is required for the last core elements, dealing with evaluating model performance.

An important challenge for the students is represented by the workload: the course covers a wide range of topics, with the students using most of their time to solve the assignments rather than deepening their understanding of theoretical concepts. This excessive focus on practical work is exacerbated by the fact that many of the students have poor programming skills, i.e. more time is required to solve the part of each assignment, which deals with coding. Nevertheless, the EnvMod course is one of the most appreciated courses in the department, always gaining a high score in the student survey for 'best course of the year'.

\section{New Problem-Based module}

According to the definition listed in Refsgaard et al. (2007) 'a person is uncertain if s/he lacks confidence about the specific outcomes of an event. Reasons for this lack of confidence might include a judgement of the information as incomplete, blurred, inaccurate, unreliable, inconclusive, or potentially false'. The structure of the EnvMod course, on the other end, runs the risk of making students overconfident about the quality of the modeling results. Presenting only one methodology to address the steps of the model building process might prevent the students from fully understanding the 
complexity of environmental modeling. This was highlighted as an issue by several teachers in specialized MSc courses, i.e. in courses that build upon the knowledge provided by EnvMod. The proposed modifications to EnvMod affected Module 5, which deals with identification of sources of uncertainty, assessment of model performance and quantification of the uncertainty of the simulated results. As shown in Table 1, the previous structure only dealt with two locations of model uncertainty (as defined in the terminology proposed by Warmink et al., 2010 and Walker et al., 2003), i.e. parameter and input uncertainty. Limiting the students' work to these two uncertainty sources might result in a biased, overconfident perspective on the model's ability to simulate environmental processes.

Two additional levels, which are essential for the professional life of future environmental engineers (namely model structural and technical uncertainty), were thus included in the module. Also, the module structure was modified from 'problemsolving group work' assignment to a 'supervised' problem-based approach. In the 'problem-solving group work' (still used in the previous four assignments) students have to solve a problem by applying a pre-defined tool and methodology. In the 'supervised' problem-based approach (Figure 2), the students are given several choices in terms of model structures and tools for model analysis (sensitivity analysis, parameter estimation, etc.). In this manner, the students were encouraged to switch from a 'passive' status ('I chose to use this model because the teacher told me to do so') to a more critical behaviour ('I chose to use this model because I think that it is more appropriate to solve my problem').

Given the characteristics of the course (a great number of students, divided in small groups of four people, the limited background of most of the students in the field of environmental modelling) a 'pure' Problem Based Learning approach was not judged to be appropriate. This was supported by the PBL discussion in Holgaard et al. (2017), which underlines the importance in allocating sufficient resources in order to better outline the problem. Given the short duration of Module 5 - it is only allocated 3 weeks - the full benefits of PBL in terms of creativity and innovation cannot be achieved. In fact, the students would not have sufficient experience and/or time to build their own understanding of the problem and then select the most appropriate tools. Instead, a 'supervised' approach ('restricted learning') was chosen: the students were given a problem to solve, but they also were provided with a range of equivalent tools. The students then discussed and decided which tools were the most appropriate for their task, and they were required to argue for their choices by using the information available in the course reading material.

The new structure of Module 5 is schematized in Figure 2 and it is subdivided into five steps: 
1) Problem is defined: students get a task, i.e. an environmental problem to solve (in 2015 the assignment dealt with modelling of wastewater flows in urban drainage systems). No indication on how the problem should be solved is provided.

2) Three different and equivalent model structures are provided. The students have to choose the model that they judge as the most appropriate to solve their task.

3) Two methods for analysing the model (sensitivity analysis) are provided. The methods differ in complexity and details of their results. The students have to choose the methods that they regard as fulfilling their needs.

4) Similar to previous step: two methods for parameter estimation are provided, with the students choosing the most appropriate for their purpose.

5) A peer review step is introduced: each group has to evaluate the work of other groups, i.e. the students have to critically analyse the work and the choices made by their peers. In this step the students do not only learn to evaluate somebody else's work, but they also get the chance to compare and critically evaluate their choices (i.e. other groups may have solved the same task in completely different manners, possibly questioning the choices made by the group being reviewed).

The increased workload associated with the new structure (e.g. by the peer review process) is compensated by a decrease in the programming assignment: the students are given turnkey models rather than having to program the models themselves. Compared to the previous assignments of EnvMod, the new structure requires fewer 'practical skills' (programming) and more 'thinking'. This is consistent with the fact that towards the end of the course a higher level of understanding is required. 

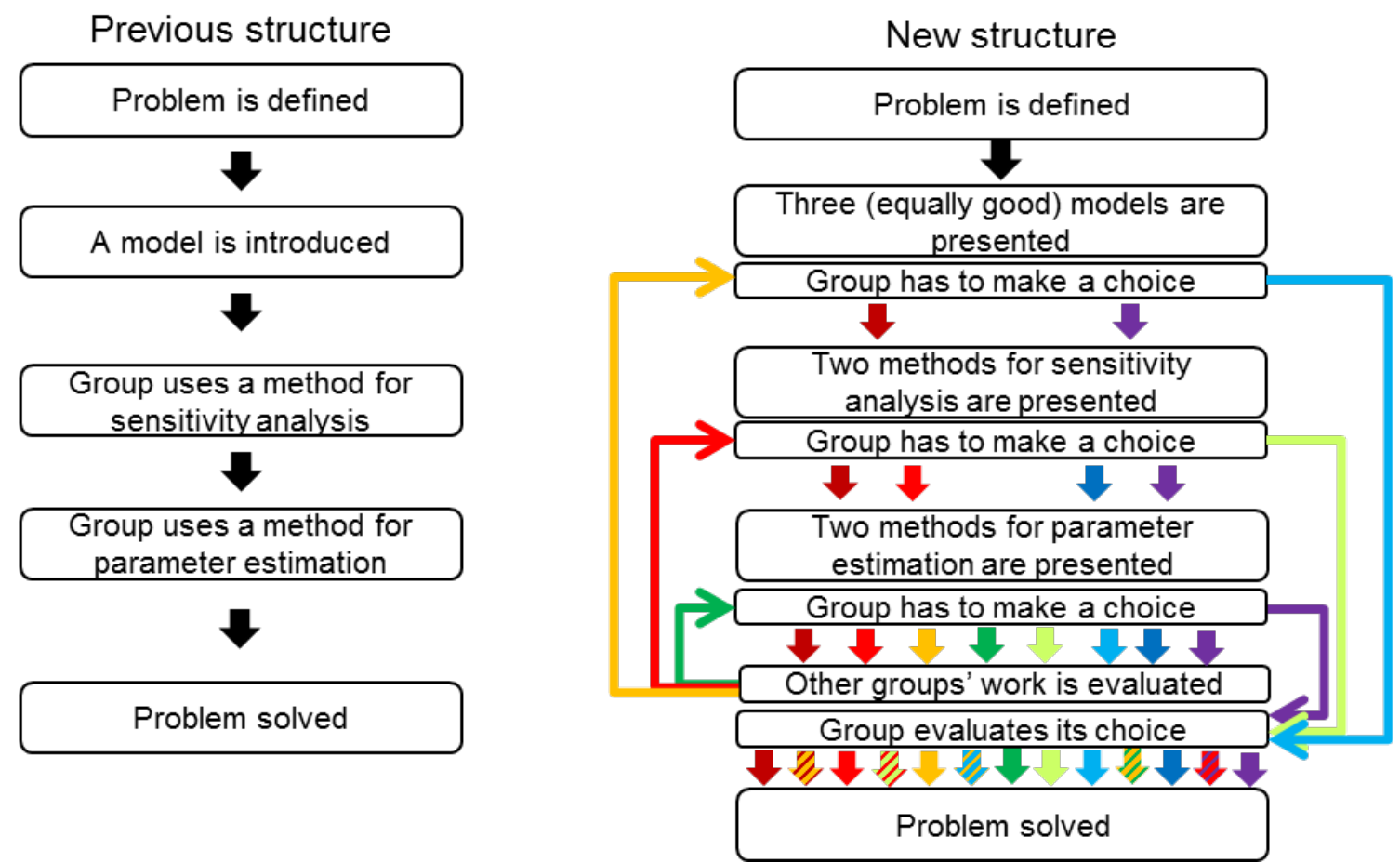

Figure 2: Schematic representation of model building exercise (adapted from Carstensen et al., 1996) and relation to the modules in the EnvMod course

\begin{tabular}{|l|c|c|c|}
\hline $\begin{array}{c}\text { Location of } \\
\text { uncertainty }\end{array}$ & $\begin{array}{c}\text { Previous } \\
\text { assignment } \\
\text { structure }\end{array}$ & $\begin{array}{c}\text { New } \\
\text { assignment } \\
\text { structure }\end{array}$ & Example \\
\hline Context & $\mathrm{X}$ & $\mathrm{X}$ & $\begin{array}{c}\text { Eack of understanding of } \\
\text { the natural process }\end{array}$ \\
\hline Input & $\mathrm{X}$ & $\begin{array}{c}\text { Effects of choices in terms of } \\
\text { software, analysis tools, } \\
\text { mathematical solvers }\end{array}$ \\
\hline Model Structure & $\mathrm{X}$ & $\mathrm{X}$ & $\begin{array}{c}\text { Different mathematical } \\
\text { descriptions for describing } \\
\text { the same natural process }\end{array}$ \\
\hline Model Parameter & & $\mathrm{X}$ & $\begin{array}{c}\text { Natural variability of } \\
\text { processes requires different } \\
\text { optimal parameter sets }\end{array}$ \\
\hline
\end{tabular}

Table 1. Schematization of locations of uncertainty (adapted from Warmink et al., 2010; Walker et al., 2003; Refsgaard et al., 2007) that are addressed in the course module. 


\section{Evaluation of the new module}

Several methods were used to monitor the implementation of the new module structure:

- A pre-testing test, carried out in the days before the start of Module 5, the results of which were actively discussed in the first class. The pre-test focuses on the preconceptions that the students might have on the applicability of environmental models, and it is therefore designed to challenge the students and their 'engineering common sense', i.e. mental structures which have been built throughout their engineering education but which might represent an obstacle to a successful use of the core elements of the course. The quiz is used to introduce and explain the structure of the assignment (which differs from the previous four).

- The standard course evaluation questionnaire, which is provided to students at the end of all the university courses and which enables comparison with previous academic years. The questionnaire also includes a free comment field, which usually provides the most important insight into the students' perception of the course (i.e. students can provide more comprehensive feedback to teachers).

- A supplementary Course Experience Questionnaire (CEQ) based on Ramsden (1991) and with specific questions developed in collaboration with the university's teaching counsellors.

- Oral feedback and discussions between teachers and students during the activities in the computer room. This oral feedback was subsequently discussed among teachers and teaching assistants.

\section{Results and discussion}

\section{Implementation}

The new Module 5 in EnvMod was introduced for the first time in the autumn semester of 2015, and it covered the last three weeks of the course. During this period, there were lectures of approximately 30-45 minutes twice a week during the first two weeks. In the last week there was a peer-review assignment, while all the remaining time (approximately 3 hours twice a week, for all the three weeks) was reserved for practical work (tutorial and exercises) in the computer room. The peer review was performed on a draft version of the final assignment, and the students had to evaluate the work of their peers based on guidelines which were presented during the lecture. Each group added the feedback they gave as appendix for the final report (i.e. the peer review was a part of the final summative assessment). 
In order to provide the students with the necessary support to complete the new formulation of the assignment, an existing tutorial was updated, and a completely new tutorial was created. All the slides from the lectures were created for this assignment (i.e. very little of the lecturing material was recycled from previous years). Only the reading material was not changed compared to previous editions of the course.

The pre-testing quiz consisted of ten questions and it was carried out in the 24-hours before the start of Module 5. The CEQ was launched in the last week of the course and it was closed at the end of the evaluation period (two weeks after the delivery of final report). Students were informed about the changes to the course structure, the reason for the increased number of tests and evaluation questionnaires that were given during the three weeks, and the fact that the new structure was developed as part of the teacher training of the author.

A total of 90 students followed the course, with 75\% answering the overall final evaluation of the course and about $69 \%$ answering the CEQ.

\section{Students' overall evaluation}

Despite the different structure compared to the previous four assignments, Module 5 was well received by the students. Based on the results from the CEQ, about $76 \%$ of the students agreed that the assignment was 'intellectually stimulating', $71 \%$ found the assignment 'motivating' and 63\% found that the assignment improved their problem skills. These results show that the main rationale behind the new module (improving critical thinking and avoiding 'passive' behaviour when applying environmental models) was successfully achieved.

The students also appreciated the peer-review exercise (where each student group had to evaluate the assignment of another group), even though this subject was not addressed in depth in any of the standard evaluation questions. Most of the groups used the entire lecture block ( 3 hours) for the peer-assessment, while they could easily have decided to complete it in the quickest possible manner ('saving' precious time to continue their work on the main report). Also, no negative comments were made on the peer-review process itself in the main course questionnaire, underlining the students' appreciation of this task.

The students actively discussed the topics related to the assignment during the lab activities, especially focusing on 'real-life' problems linked to e.g. data availability, computational resources, project time management. These discussions increased the students' awareness of the uncertainty linked to the application of environmental models.

A main reason for this successful implementation can be traced to the careful planning of the new module. After discussions with the fellow teacher trainee and the 
teaching counsellors, the new structure was also thoroughly discussed with the course leaders, which meant it was possible to fine-tune the workload and lecture content to the skills of the students. Close interaction with the course teaching assistants also ensured that the exercises and tutorials matched the level of the course. This is part of the 'quality assurance' that has ensured that the EnvMod course has been highly rated over the years, despite substantial changes in its content.

\section{Pre-testing quiz}

The pre-testing quiz was designed to challenge the students and their 'engineering common sense'. The quiz was mainly intended as a tool to introduce the new module, and its results were used to exemplify some of the issues that were subsequently addressed during the course. The students had limited time to answer the questions, and they were expressly invited not to use more than 10 minutes to answer the entire questionnaire (i.e. a maximum of 1 minute per question). This was intended (i) not to increase the workload of the students, and (ii) to force the students to give a quick, not well reasoned answer, in order to highlight their pre-concepts, which might lead them to non-optimal choices (in an environmental engineering context).

However, several students complained about the pre-testing quiz, and they considered it a waste of their time. After a discussion with the fellow teachers, several factors were suggested to explain this negative feedback:

1) Scheduling of the quiz: there was an overlap with the deadline for the previous assignment (Module 4), resulting in an increase in student stress;

2) The discussion of the quiz results was carried out orally and - despite serving as an introduction to the module - was not seen by the students as 'useful teaching', i.e. without theoretical content that could help them pass the final exam;

3) The early scheduling of the lectures (starting at 08.00), which meant that almost half of the students entered the classroom 15-20 minutes after the start and thus missed an important part of the introduction and quiz discussion.

\section{Course Experience Questionnaire}

The average CEQ scores are listed in Table 2. Generally, all the scales scored above the average, with the exception of the appropriate workload (AWS). The workload is a major issue in EnvMod, and Module 5 was not an exception. Almost 57\% of the students answered that they had too little (or just enough) time to fully understand the topic of the assignment. 
Based on the students' comments, additional stress factors, which were specific for Module 5 were identified as:

1) Structure of the tutorials: the main structure of the two tutorials given to the students (both the updated and the new one) was not changed in the new version of the module. The tutorials consisted of a series of steps and procedures that the students had to follow to be able to run the models and to complete the assignment. No clear explanation of these steps (e.g. why the students had to make that specific step) was provided in the tutorial, which therefore lacked a clear connection with the theory which was illustrated in the lectures. This structure did not align with the main philosophy of Module 5- 'understand what you are doing' - which meant that the students had to do additional work.

2) Practical issues linked to the code: the use of new models and of new codes resulted in small software errors, which were promptly corrected during the lab exercises by the teaching assistants. Despite being minor issues, which were solved in a short amount of time, these delays added up in an already tight course schedule, resulting in the perception of an increased workload.

\begin{tabular}{|l|l|}
\hline Scale & Average Value \\
\hline Good teaching (scale) [GTS] & 3,80 \\
\hline Clear Goals and Standards (scale) [CGS] & 3,31 \\
\hline Appropriate Workload (scale) [AWS] & 2,90 \\
\hline Generic Skills (scale) [GSS] & 3,53 \\
\hline Motivation (Scale) [MS] & 3,66 \\
\hline
\end{tabular}

Table 2. Average scales of the Course Experience Questionnaire.

Another index which could be identified as problematic is the Clear Goal and Standards (CGS) scale. In the questions related to CGS, a group of 15-20 students (around one third of the student who responded to the (EQ) chose values below the average, with the greatest number (21) expressing values below the average for the question 'It was often hard to discover, what was expected of me in this assignment'. A partial explanation for this is the inherent structure of the assignment: given the different combination of models and tools, the students had at least 12 different ways of solving the same assignment. 
Therefore, the requirements for the assignment were quite generic (e.g. one of the questions introducing the choice of the model was 'Use your current professional knowledge in the choice (e.g. hydrology). Do not choose randomly, but find some arguments behind your choice'), and some students might have found it difficult to organize their work based on these open-ended questions.

Furthermore, some of the comments suggested that the requirements for the draft report that had to be evaluated in the peer review were not really defined. This was a deliberate choice (students had to submit what they had prepared by the deadline) that was made to avoid putting further stress on the students. However, this might have contributed to the students feeling unclear about the expected standards.

High scores were obtained for the Motivation Scale (MS) and Good Teaching Scale (GTS). The entire assignment was designed to encourage active learning from the students by not simply asking them to follow a list of programming instructions. The students learnt about the different structure of the assignment compared to the rest of EnvMod during the first lecture, and they were reminded about the importance of using a critical approach in their choices throughout the entire assignment. All these elements have helped to motivate the students, thereby resulting in a good MS value. Similarly, the teaching team put a lot of effort into delivering the new model and the students recognized this input.

\section{Standard course evaluation questionnaire}

The overall evaluation of EnvMod was in line with the previous year when it was among the department's best scoring courses. There were no specific comments about the new formulation of Module 5. This suggests that the new module was well integrated in the course, maintaining the overall 'storyline' and high quality. Specific comments were made on the theoretical level of the lectures and on the understanding of modelling tools provided in Module 5.

The lectures were organized to provide a general overview of the different tools and topics, and they were limited to 30-45 minutes for each teaching day. A detailed description of the methods and tools that were introduced in class was available on the course homepage. However, the link between the reading material and the lecture topics was not clear to all the students.

The students were provided with pre-compiled models to reduce the 'uncritical' workload for the students (i.e. programming): the students had only to make minor modifications to the code in order to complete the assignment. Although this situation resembles real life applications, where practitioners apply environmental models without spending time on a detailed analysis of the simulated processes, some students were frustrated by this approach. Some of the most active student groups asked for detailed information about the code and models, and they could easily handle this detailed information. On the other hand, other groups had a limited 
knowledge of the programming language (MATLAB), and they showed difficulties handling the limited programming work required in the assignment.

Overall, there was an alignment between the CEQ and the standard course evaluation. The majority of the students gave positive feedback about the proposed changes, and were appreciative of the new teaching method that was used.

\section{Assessment of students' learning}

The formative assessment was mainly carried out through interaction with the students during lab activities in the computer room. Given the high number of students and the physical settings for these activities (students were working in two different rooms), it was only possible to interact with a limited number of students at any one time. Issues that arose during these activities were subsequently addressed in the following lecture for the whole class. Therefore, the formative assessment had a direct influence on the lectures' content.

Both the final grading of students' reports and the formative assessments supported the fulfilment of Module 5 learning objectives (LO), namely the utilization of state of the art modelling tools and the integration of models with data from real environmental systems. The students, in fact, encountered some of the typical challenges faced by environmental engineers in real-life applications. For example, the available model structures failed to describe all the processes that were described by the available datasets. This underlined the models' structural limitations, and prompted the students to reflect on the various sources of uncertainty affecting their model simulation results.

The peer review exercise forced the students to critically analyse the work of their peers, as well as their own work. The students were explicitly invited to focus on the arguments used in the reports, rather than looking at 'marginal issues' (with respect to the LO), such as calculation errors or report layout. The level of the analyses performed during the peer review was consistent with the overall level of understanding of each group: student writing good reports, showing a deep knowledge of the topic, also wrote good reviews. It should be noted that the students had to review reports from groups with similar skills (trying to avoid the situation where good students had to review poor reports, and could not show their full understanding of the topic, or poor students reviewing good reports but providing poor feedback).

Since EnvMod is timetabled in the first semester of the MSc education and the LO cover medium-low levels of the Bloom (SOLO) taxonomy, students were presented with different models and tools (which can be applied in the following steps of their MSc education) and detailed, deep theoretical descriptions of the methods were not included in the teaching. However, the students will benefit from most of the compe- 
tences gained in EnvMod in the other modelling courses, as well as in their future engineering careers.

The results of the summative assessment of Assignment 5 were in line with the results of the previous assignments (see Figure 3), suggesting that the level of understanding of the different student groups was not significantly affected by the switch from problem-solving to a problem-based learning approach. Groups that performed well in the previous part of the course also had a good grade in Module 5, and vice versa.

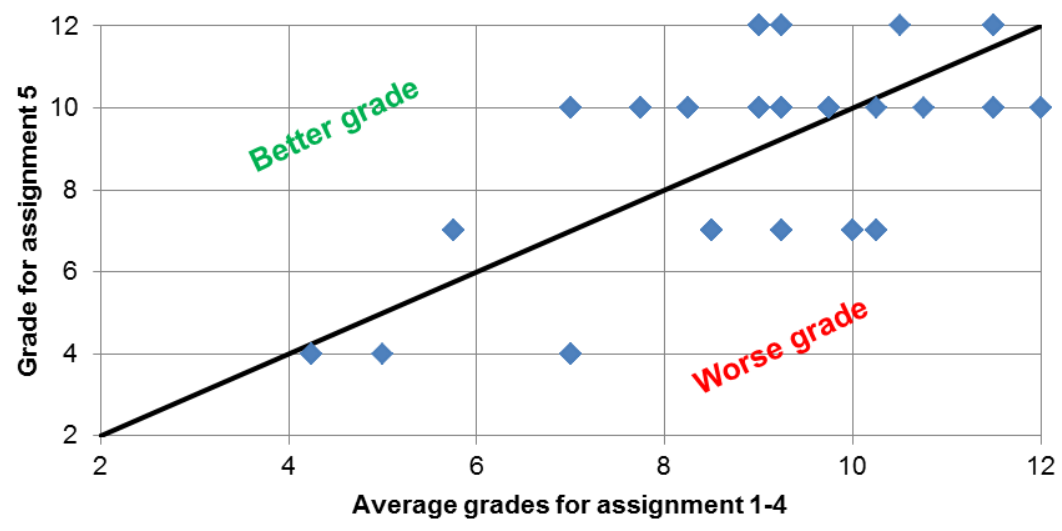

Figure 3: Comparison between average grades obtained for assignment 1-4 and the grades obtained for assignment 5.

Also, the results of the oral examination were in line with those of the written report: no major changes in the grade had to be made after the exam, when compared to the initial grade based on the reports. Evaluation of group reports cannot clearly show if all the students had achieved all the desired LO (for example, work subdivision within a student group might result in a student achieving a LO but neglecting another one, and vice versa). However, the alignment between the written and the oral examination confuted this concern, suggesting that all the students had achieved the desired LO for Module 5.

Overall, the effect of the different working approach required in Module 5 (compared to previous assignments) can be exemplified by one of the comments in the standard questionnaire: 'It's a good final assignment, where you think a bit more about what your model actually does, rather than just trying to make it work'. This shows how this student felt that he/she had achieved a wider perspective on applications of environmental models (i.e. confidence in the model results), rather than focusing on low-level issues (e.g. debugging).

Improvements based on students' feedback

Given the positive feedback for the new structure of Module 5, the structure was permanently adopted in EnvMod and it was successfully taught in autumn 2016 and 
2017. Based on the detailed feedback from the 2015 semester, the following improvements were made:

- The pre-testing quiz was modified: to avoid overlapping with other deadlines, the quiz was performed during the first class by using an on-line response platform (clickers)

- The workload was decreased, by improving the tutorials and bug-checking all the code. Also, explicit references to the teaching material and lecture topics were included in the tutorials.

The theoretical content of the lectures was slightly increased (around 10 minutes) without changing the complete philosophy behind EnvMod (with most of the course time still spent in the computer room). Links between the topics introduced in class and the available reading material were created. Even though this does not fit with the philosophy of a 'pure' Problem-Based-Learning, when students would be expected to find relevant information by themselves, it was a useful adaptation considering the limited time available.

Additionally, some students suggested that Module 5, which focuses on analysing the behaviour of model tools (rather than creating a new model, as is the case in other EnvMod assignments) could be built upon some of the models from the previous assignments. This possibility is still under implementation for the next editions of EnvMod.

\section{Conclusion}

This case study demonstrates how complex concepts such as uncertainty in the application of environmental models can successfully be integrated in existing courses. The implementation of the new Problem-Based structure, judged as the most appropriate to achieve the learning objectives of Module 5 of EnvMod, was a great success. The critical thinking of students was improved, as well as their understanding of the concepts involved in uncertainty analysis. This is an essential skill for a successful application of environmental models.

The students worked with different tools for uncertainty analysis, addressing an increased number of sources of uncertainty, such as model structural uncertainty and model technical uncertainty. Despite several constraints such as limited time (only three weeks), the high number of students (90) with different background knowledge (for the majority of students this was their first semester of the MSc education), the balance between practical work and lecturing (with the latter reduced to only 30-45 min), the new structure successfully achieved the intended Learning Objectives. This has been supported by careful planning from the teaching team and by the tools 
provide by the teaching counsellors as part of the university teaching training programme.

The constraints posed by the EnvMod course required an adaptation of the 'pure' Problem-Based Learning approach in order to avoid an increase in the students' workload. The substitution of the previous 'restricted' problem-solving with an openended assignment received positive feedback from the students. This assignment, where the same task could be completed in different manners, resembles real-life cases, where environmental modellers can make several subjective choices that affect their final results. The use of peer-review to increase awareness of these sources of uncertainty proved to be effective.

The evaluation tools that were set up as part of the university teaching programme (e.g. CEQ) gave useful insights into the students' learning processes and provided feedback for improvements of EnvMod. The students are now able to successfully work with the complex but essential topic of uncertainty in environmental modelling, making them capable of applying the most appropriate modelling tools to solve environmental problems.

\section{References}

Beven, K. J. (2009) Environmental Modelling: An Uncertain Future? An Introduction to Techniques for Uncertainty Estimation in Environmental Prediction, Routledge.

Biggs, J. and Tang, C. (2011) Teaching For Quality Learning at University: What the Student Does, McGraw-Hill/Society for Research into Higher Education/Open University Press

Carstensen, J., Vanrolleghem, P. A., Rauch, W., and Reichert, P. (1997) Terminology and methodology in modelling for water quality management - a discussion starter. Water Science and Technology, 36(5), 157-168

Holgaard, J. E., Guerra, A., Kolmos, A., and Petersen, L. S. (2017) Getting a hold on the problem in a problem-based learning environment. International Journal of Engineering Education, 33(3), 1070-1085.

Jakeman, A. J., Letcher, R. A., and Norton, J. P. (2006) Ten iterative steps in development and evaluation of environmental models. Environmental Modelling and Software, 21(5), 602-614.

Matott, L. S., Babendreier, J. E., and Purucker, S. T. (2009) Evaluating uncertainty in integrated environmental models: A review of concepts and tools. Water Resourches Research, 45(6), W06421

Ramsden, P. (1991) A Performance Indicator of Teaching Quality in Higher Education: The Course Experience Questionnaire. Studies in Higher Education, 16(2), 129150. 
Refsgaard, J. C., van der Sluijs, J. P., Højberg, A. L., and Vanrolleghem, P. A. (2007) Uncertainty in the environmental modelling process - A framework and guidance. Environmental Modelling and Software, 22(11), 1543-1556.

Voinov, A. and Shugart, H. H. (2013) "Integronsters", integral and integrated modeling. Environmental Modelling and Software, 39, 149-158

Walker, W. E., Harremoës, P., Rotmans, J., van der Sluijs, J. P., van Asselt, M. B. A., Janssen, P., and Krayer von Krauss, M. P. (2003) Defining Uncertainty: A Conceptual Basis for Uncertainty Management in Model-Based Decision Support. Integrated Assessment, 4(1), 5-17.

Warmink, J. J., Brugnach, M., Vinke-de Kruijf, J., Schielen, R. M. J., and Augustijn, D. C. M. (2017) Coping with Uncertainty in River Management: Challenges and Ways Forward. Water Resources Management, 31(14), 4587-4600.

Warmink, J. J., Janssen, J. A. E. B., Booij, M. J., and Krol, M. S. (2010) Identification and classification of uncertainties in the application of environmental models. Environmental Modelling and Software, 25(12), 1518-1527.

Zhou, C. (2012) Fostering creative engineers: a key to face the complexity of engineering practice. European Journal of Engineering Education, 37(4), 343-353. 